\title{
CAPACITAÇÃO PARA O COMBATE E PREVENÇÃO DE INCÊNDIOS FLORESTAIS NA REGIÃO DO ALTO IRANI - SC
}

\author{
Walter Parizotto ${ }^{1}$ \\ Nestor Fernandes da Silva ${ }^{2}$ \\ Genésio Téo
}

\begin{abstract}
RESUMO
A região do Alto Irani situada no oeste catarinense, possui $15 \%$ da vegetação original, tem caracteristicamente a silvicultura praticada em áreas inferiores a 10 hectares, registra índices preocupantes de incêndios florestais, principalmente em reflorestamentos. Como inexiste na região qualquer programa oficial sendo desenvolvido por órgão público, a Universidade do Oeste de Santa Catarina - UNOESC, através do seu campus de Xanxerê, desenvolveu um projeto de capacitação que inclui bombeiros, trabalhadores de empresas florestais, funcionários públicos com função de extensão rural e representantes das comunidades indígenas. O projeto de extensão universitária é oferecido gratuitamente, tendo por objetivos difundir técnicas de queima controlada para os agricultores, técnicas de prevenção para pequenos e médios silvicultores, qualificação técnica a bombeiros visando o desenvolvimento de atividades de prevenção e combate e, principalmente, a composição de uma força tarefa qualificada para o combate a incêndios florestais em todos os 14 municípios da região.

Palavras chaves: Extensão universitária, incêndios florestais.
\end{abstract}

\begin{abstract}
The region of Alto Irani situated in the west of Santa Catarina possesses $15 \%$ of its original vegetation, characteristically it has silviculture practiced in areas inferior to 10 hectare, registers worrying indexes of forest fires, mainly in areas of reforestation. As there is not in the region any official program being developed by a public department, the Universidade do Oeste de Santa Catarina - UNOESC, via its campus situated in Xanxerê, developed a qualification project that includes firemen, workers from forest companies, public officers whose function is rural extension and representatives of Indian communities. The university extension project is offered free of charge, it has as objectives to spread techniques of controlled burn for the agriculturists, techniques of prevention for small and medium silviculturists, technical qualification for firemen with the objective of developing activities for prevention and combat of fires and mainly the composition of a group qualified for fighting against forest fires in all the 14 cities in the region.
\end{abstract}

Key words: university extension, forest fires.

\section{INTRODUÇÃO}

Os incêndios constituem sem dúvida a maior ameaça que os espaços florestais enfrentam.

O homem e os incêndios sempre tiveram uma estreita relação, principalmente porque aquele é o principal responsável pelas suas ocorrências. Não difere do processo histórico registrado na região do Alto Irani, situada no oeste catarinense. Atualmente remanesce aproximadamente $15 \%$ da vegetação original já que o restante foi dizimado para dar lugar a plantações de soja, milho e trigo sendo que atualmente surgem as plantação de florestas comerciais. Com relação a silvicultura, essa tem, caracteristicamente, sido praticada em áreas inferiores a 10 hectares. Pelas questões históricas e pela falta de ordenação florestal a região registra índices

\footnotetext{
${ }^{1}$ Oficial do Corpo de Bombeiros do Estado de Santa Catarina, Mestrando em Eng. Florestal UFPR, Especialista em controle de incêndios florestais, Av. Brasil 2685 - Xanxerê -SC-2bbm2c4p@pm.sc.gov.br.

${ }^{2}$ Pró-reitor de ensino pesquisa e extensão Universidade do Oeste do Estado de Santa Catarina, campus Xanxerê, Mestre em educação, pedagogo. Bairro universitário - Xanxerê -SC

${ }^{3}$ Pró-reitor de administração da Universidade do Oeste do Estado de Santa Catarina, campus Xanxerê, mestre em administração, administrador. Bairro universitário - Xanxerê -SC
} 
preocupantes de incêndios florestais, principalmente em reflorestamentos. Como inexiste na região qualquer programa oficial sendo desenvolvido por órgão público, visando a minimização do problema, a Universidade do Oeste de Santa Catarina - UNOESC, através do seu campus de Xanxerê, desenvolveu um projeto de capacitação que incluiu bombeiros, trabalhadores de empresas florestais, funcionários públicos, estes principalmente ligados a prefeituras municipais com função de extensão rural e representantes das comunidades indígenas. $\mathrm{O}$ projeto de extensão universitária foi oferecido gratuitamente e teve por objetivos principais difundir técnicas de queima controlada para os agricultores, técnicas de prevenção para pequenos e médios silvicultores, qualificação técnica a bombeiros visando o desenvolvimento de atividades de prevenção e combate e principalmente a composição de uma força tarefa qualificada para o combate a incêndios florestais em todos os 14 municípios da região.

Desta forma, cientes de que os incêndios florestais constituem um dos fatores que mais contribuem para a redução das florestas em todo o mundo torna-se obrigação das instituições constituídas e dever de cada cidadão preservar as florestas nativas, combater a prática ilícita da queima e do desmatamento da cobertura vegetal natural.

\section{A região do Alto Irani}

A região do Alto Irani localiza-se no oeste do estado de Santa Catarina, sendo formada por 14 municípios, (fig 1) tendo uma área de $4960 \mathrm{~km}^{2}$, que corresponde a 5,2\% da área do Estado. Situa-se entre os paralelos $26^{\circ}$ $57^{\prime} 42^{\prime \prime}$ e $26^{\circ} 27^{\prime} 18^{\prime \prime}$ de latitude e $52^{\circ} 41^{\prime} 09^{\prime \prime}$ de longitude; a cobertura vegetal é composta por florestas nativas remanescente da floresta ombrófila mista (mata com araucária), floresta estacional decidual (mata caducifólia /Subtropical) e áreas de reflorestamento.

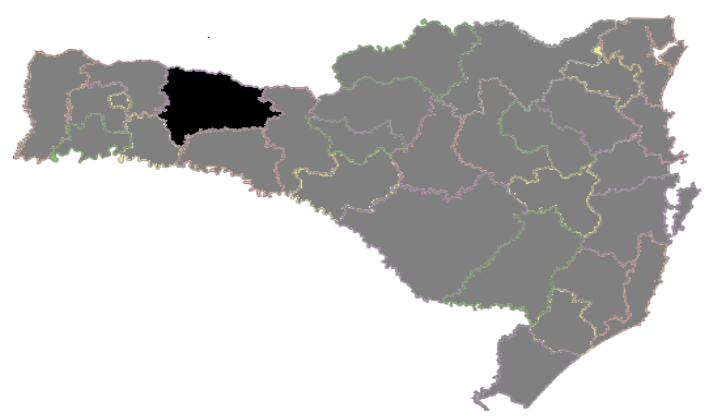

Figura 1 - Região do Alto Irani - SC/ Region of Alto Irani - SC

O estado de Santa Catarina descobriu há pouco tempo sua vocação para o setor florestal nas terras pobres do planalto. Estas terras exigiam um alto custo para agricultura de grãos, mas mostraram-se adequadas para a silvicultura, representando lucro e produtividade. As antigas fazendas de gado, hoje se revestem de verde e concedem lugar a exuberantes florestas de pinus. Nas terras férteis, porém dobradas do Oeste, nasce uma nova fronteira da silvicultura se apresentando como alternativa para a crise da agricultura de subsistência e da impossibilidade de mecanização das atividades agrícolas nos terrenos acidentados.

Aliado a isso a Região possui uma área vegetal de importância ecológica muito grande devido aos remanescentes florestais existentes. Sendo assim, preservar a diversidade vegetal de uma região é cada vez mais uma necessidade e um desafio, uma vez que possuímos índices alarmantes de degradação ambiental no país, tendo como principal vetor desta degradação o uso descontrolado de queimadas no setor agrícola. Atualmente a exploração florestal corresponde a $4 \%$ do Produto Interno Bruto - PIB do país, o que representa a necessidade crescente dos seres humanos em extrair o máximo de lucro da natureza e do solo, em uma luta desigual, nesta sociedade capitalista que conhecemos.

Calcular e demonstrar o valor da biodiversidade e dos recursos naturais e a influência destes na economia não é uma tarefa 
fácil, pois este valor é determinado por uma variedade de fatores econômicos e éticos que envolvem toda a sociedade. Incorporar a preservação da biodiversidade regional significa entender o extremo valor da natureza para a existência humana através da mudança de mentalidade, o que acontecerá somente quando as pessoas perceberem que estão perdendo algo que lhes é fundamental. É necessário compreender que somente com a manutenção da diversidade biológica encontraremos o caminho para uma vida de qualidade.

Este estudo direciona-se, como citado anteriormente, a região do Alto Irani, e desta merecem atenção especial três formações vegetais originais. $\mathrm{Na}$ cidade de Entre Rios encontra-se a maior área florestal ainda intocada do oeste de Santa Catarina. Essa floresta de forma particular sofre anualmente sérias pressões em decorrência de estar situada dentro de uma reserva indígena, cujas práticas agropastoris ainda incluem $\mathrm{o}$ uso de queimadas.

No município de São Domingos, foi criado no ano de 2002, o Parque Estadual das Araucárias, a única área de preservação permanente de jurisdição estadual em todo o Oeste Catarinense. Nas cidades de Passos Maia, Ponte Serrada, Vargeão e Abelardo Luz, forma-se a maior reserva de araucárias do planeta, de propriedade particular.

\section{Evolução do setor madeireiro}

A região começou a ser colonizada em 1885. Juntamente com os primeiros colonos vieram também madeireiros, pois era preciso derrubar as centenárias araucárias para dar lugar às novas lavouras. A região foi habitada por índios guaranis e kaingangs até o início do Século XX, quando iniciou o ciclo da madeira e a criação de gado. Tempos depois, o deslocamento de imigrantes do Rio Grande do Sul trouxe descendentes de italianos e de alemães para a região.

Nessa época em todos os povoados existia uma ou mais madeireiras, que cresceram e mantiveram-se como principal fonte de geração de empregos e riquezas na região até a década de 70 e 80 , quando muitas fecharam ou transferiram-se para o norte do país. Algumas poucas que investiram no reflorestamento permaneceram e se fortaleceram e muitas das originais madeireiras de extração de araucárias, imbuias, canelas, angicos, bracatingas, dentre outras, mudaram seu ramo e de antigas serrarias que fabricavam tábuas, tornaram-se fábricas de papel e celulose, portas, compensados, artefatos de madeira e semelhantes.

$\mathrm{Na}$ região do Alto Irani, as antigas serrarias que subsistiam apenas do extrativismo modificaram sua perspectiva e se fortaleceram a partir de florestas plantadas e como cada vez mais aumenta a pressão contra o corte de áreas naturais, maior é a valorização de áreas reflorestadas.

\section{Incêndios e a questão histórica agrícola}

Análogo ao declínio da floresta natural, os incêndios em florestas na região do Alto Irani estão associados à evolução da lavoura. Não há ponto sem cobertura natural na região que não ardeu em uma fogueira durante a fase de colonização. Até os dias atuais a prática de queimadas para limpeza préplantio é largamente utilizada pelos agricultores da região.

A existência de várias áreas indígenas na região, principalmente nos municípios de Ipuaçu, Entre Rios e Abelardo Luz, onde os agricultores ainda usam técnicas milenares para o preparo do terreno para o plantio, tem contribuído para a eclosão de grandes incêndios todos os anos, sendo que o maior já registrado ocorreu no ano de 1999 , onde foi queimado aproximadamente $30 \%$ da área, na reserva indígena Xapecó, que têm 16 mil hectares. Duas casas também foram totalmente queimadas nesse incêndio, felizmente não foi registrado nenhuma vítima.

\section{Universidade do Oeste de Santa Catarina - UNOESC, extensão e ação comunitária}

A extensão na Universidade do Oeste de Santa Catarina - UNOESC, foi pensada enquanto política oficial somente em 1994, por meio da Resolução $\mathrm{n}^{\mathrm{o}}$ 43, do Conselho de Ensino, Pesquisa e Extensão. Isto significa afirmar que a Instituição considera a extensão, juntamente com o ensino e a pesquisa atividades-fim de uma universidade. Diversos programas, foram desenvolvidos nesses anos todos, sobretudo programas/projetos na área social, uma vez que a UNOESC é mantida por uma Fundação de caráter filantrópico. 
A extensão e a ação comunitária fundamentam-se nos pressupostos de que: a UNOESC é uma Instituição de origem pública e, enquanto tal, é chamada a responder às exigências e demandas regionais colocadas pela problemática que envolve os mais de cem municípios de seu entorno; a extensão e a ação comunitária constituem-se em lugares privilegiados para estabelecer-se uma relação de reciprocidade e parceria entre a UNOESC e a comunidade regional, dado o seu caráter público e social; a regionalidade de atuação da UNOESC, hoje uma marca, uma identidade e um diferencial de seu escopo conceitual, deve ser entendida como categoria que articula o local, o regional e o global, na perspectiva do desenvolvimento sustentável; a legitimidade de uma instituição universitária se conquista com o modo e a intensidade de seu engajamento na solução dos problemas de seu entorno, tornando suas atividades-fim relevantes, não somente do ponto de vista acadêmico, como do ponto de vista de sua pertinência para o processo de desenvolvimento regional; na sua interface com o ensino, a extensão e a ação comunitária contribuem para o desenvolvimento do processo ensinoaprendizagem, possibilitando o envolvimento dos acadêmicos com a prática do conhecimento; na sua interface com a pesquisa, a extensão e a ação comunitária respondem cientificamente às demandas suscitadas pela comunidade; a extensão e a ação comunitária, comprometidas com a produção e socialização do conhecimento científico, tecnológico e artístico-cultural, reforçam o compromisso social da UNOESC em promover o acesso ao conhecimento que produz e de que dispõe; pela extensão e pela ação comunitária, possibilita-se o desenvolvimento integral da pessoa, bem como o seu preparo para o exercício da cidadania e sua qualificação para o trabalho, na medida em que apontam para práticas coletivas que sejam integrais na sua relação pessoal, mobilizadoras nas suas opções ética e cidadã e comprometidas com suas ações políticas e sociais.

O Corpo de Bombeiros, sediado na cidade de Xanxerê, realizou uma pesquisa junto aos principais produtores florestais, empresas do setor e secretarias de agricultura, visando apontar um diagnóstico do setor florestal na região.

Os resultados obtidos apontam para uma situação preocupante. Os principais problemas apontados foram os seguintes:

a) Inexistência de silvicultura preventiva: caracterizada pela produção em pequenas e médias empresas, o incentivo para o plantio resulta, geralmente, das prefeituras que na maioria dos municípios é quem fornece as mudas. Nenhuma das prefeituras da região emprega em suas secretarias de agricultura algum engenheiro florestal, e a Associação de Engenheiros do Alto Irani - SEAI registra apenas dois profissionais em atuação na região. A falta de qualificação técnica e de acompanhamento resulta em uma silvicultura desorganizada, com pouquíssimas ações preventivas estruturais;

b) Poucas unidades de bombeiros, falta de estrutura e qualificação dos profissionais bombeiros existentes: existem apenas 3 unidades de bombeiros, instaladas em $2001 \mathrm{e}$ 2002 respectivamente nas cidades de Xanxerê, Xaxim e Ponte Serrada. Antes da implantação do projeto que vai-se discorrer abaixo apenas um bombeiro possuía treinamento de combate e conhecimento e ações de prevenção;

c) Inexistência de registro e perícias nos incêndios florestais;

d) Inexistência de treinamento e qualificação para os trabalhadores florestais e profissionais ligados a floresta;

e) Falta de monitoramento de risco e vigilância em áreas potencialmente importantes;

f) Falta de punição para queimadas irregulares;

Foi após o resultado da pesquisa supra que surgiu a idéia da parceria entre o Corpo de Bombeiros Militar do Estado de Santa Catarina, através de seu pelotão com sede em Xanxerê e a Universidade do Oeste de Santa Catarina - UNOESC, campus da mesma cidade, para o desenvolvimento de um treinamento de controle de incêndios florestais básico.

Como inexiste na região qualquer programa oficial sendo desenvolvido por órgão público, a UNOESC, através do seu campus de Xanxerê, entendeu que embora não tenha participação direta no controle de incêndios florestais, suas ações poderiam contribuir para 
amenizar o problema. Assim desenvolveu um projeto de capacitação que incluiu a participação de bombeiros, trabalhadores de empresas florestais, funcionários públicos com função de extensão rural e representantes das comunidades indígenas.

O projeto de extensão universitária foi oferecido gratuitamente, tendo por objetivos: difundir técnicas de queima controlada para os agricultores, técnicas de prevenção para pequenos e médios silvicultores, qualificação técnica a bombeiros visando o desenvolvimento de atividades de prevenção e combate e, principalmente, a composição de uma força tarefa qualificada para o combate a incêndios florestais em todos o 14 municípios da região.

O corpo docente foi formado por especialistas, em incêndios florestais, biólogos e Bombeiros.

$\mathrm{O}$ primeiro treinamento foi realizado em 16 e 17 de junho de 2003 e teve a participação de 32 alunos, sendo que na sua maioria eram bombeiros. Contou também com a adesão de professores, técnicos em segurança do trabalho e trabalhadores de empresas do setor florestal.

$\mathrm{O}$ segundo treinamento foi ministrado nos dias 20,21 e 22 de novembro e o público alvo foi membros de ONGs, funcionários de prefeituras, principalmente de secretarias de agricultura com função de difusão de técnicas agrícolas, bombeiros e profissionais que desenvolveram ações no Parque Estadual das Araucárias, na cidade de São Domingos. Nesse curso foram formados 18 alunos.

A grade curricular foi desenvolvida a partir de um resumo conceitual do programa que foi planejado com base no modelo do Instituto Brasileiro do Meio Ambiente e dos Recursos através do trabalho desenvolvido por SILVA (1998), cujo texto visa oferecer subsídios a qualificação de brigadistas. Considerando que além de combatentes, este projeto teve como escopo formar pessoas com conhecimento crítico para o diagnóstico de seus espaços e buscar soluções elementares. Diante desse objetivo foram dedicados 04 horas/aula para conceitos fundamentais e princípios gerais dos incêndios florestais, 04 horas/aula para o estudo dos efeitos do fogo nos ecossistemas, 06 horas/aula para prevenção dos Incêndios Florestais, 06 horas/aula para conceitos teóricos para $\mathrm{o}$ combate aos incêndios florestais e por fim 06 horas/aula destinada a prática de Combate e controle a incêndios Florestais

\section{RESULTADOS}

A mudança de paradigma é uma tarefa difícil. Duas situações concomitantes estão sendo desenvolvidas, uma diz respeito a mudança da cultura florestal, com a implantação de florestas plantadas e da mudança das práticas de queimadas pelos proprietários das pequenas e médias propriedades rurais, outra diz respeito a implantação de unidades de Corpos de Bombeiro na região.

O desenvolvimento desse projeto foi a primeira ação voltada para a questão dos incêndios florestais no oeste de Santa Catarina. Com a formação das equipes que participaram da capacitação, municípios em que antes não havia qualquer interesse em prevenir seus incêndios florestais, onde sequer acionavam socorro, passaram a ter uma preocupação maior e mais consistente.

Notou-se que a partir desses eventos, as unidades de bombeiros passaram a ser solicitados constantemente para a realização de palestras para trabalhadores de empresas do setor florestal da região, especificamente sobre ações de primeira intervenção. Em resultado a isto foram realizadas 8 palestras na região, solicitadas por participantes dos cursos que entenderam a importância do projeto e levaram a idéia para seus superiores.

Os Corpos de Bombeiro buscaram equipar-se melhor, adquirindo materiais específicos para o combate a incêndios florestais em todas as três unidades, bem como todos passaram a monitorar os incêndios ocorridos, onde passou-se a ter um registro da extensão, das causas prováveis e do prejuízo estimado, bem como um pequeno histórico das ações de combate.

Uma questão positiva denotada desse projeto diz respeito ao uso e gestão do Parque Florestal das Araucárias, cujo projeto está sendo desenvolvido como proposta pela UNOESC ao órgão que administra o parque e que prevê que todo e qualquer projeto lá desenvolvido, além do impacto ambiental, deverá vir corroborado de planos de ações 
voltados a redução do risco de eclosão e propagação de incêndios.

Resultados também foram percebidos no município de Passos Maia, onde pequenos e médios silvicultores associaram seus meios logísticos para a aquisição de equipamentos e formação de brigadas em comum.

\section{CONCLUSÃO}

A problemática dos incêndios florestais tem muitas faces e a solução para minimização dos seus impactos é complexa. No entanto a experiência desse projeto tem mostrado que não existem técnicas universais. Ainda há muita informação para chegar até a ponta, onde estão os operadores da floresta e os combatentes de incêndios. A causa e a solução para os incêndios florestais ocupam o mesmo espaço.

O problema torna-se mais simples quando mais pessoas estão envolvidas e admitem que a solução também é de sua responsabilidade. Essa foi a motivação principal do projeto desenvolvido pela Universidade do Oeste de Santa Catarina UNOESC, em seu campus de Xanxerê, onde embora não tenha aparentemente nenhum interesse direto com incêndios florestais, entendeu que sua participação seria fundamental na minimização do problema.
A ação educativa promovida através do oferecimento de um curso de extensão em combate e prevenção de incêndios florestais levou em conta a necessidade regional de oferecimento de capacitação profissional aos trabalhadores que já estão integrados aos sistemas econômicos da região e também da necessidade de difundir a idéia de que a preservação dos recursos naturais. Esta é uma perspectiva necessária quando se pretende promover o desenvolvimento sustentado com qualidade de vida para a população local.

Promover o conhecimento e o desenvolvimento regional é a contribuição da extensão universitária para a sociedade, fortalecendo parcerias em busca do pretendido exercício da função social da Universidade.

\section{REFERÊNCIA}

SILVA, Romildo Gonçalves da. Manual de prevenção e combate aos incêndios florestais. Brasília: Instituto Brasileiro do Meio Ambiente e dos Recursos Renováveis, 1998.

SOARES, R.V, BATISTA, A. C. Prevenção dos Incêndios Florestais. Associação Brasileira de Agricultura Superior, Universidade Federal do Paraná, Curso de Especialização - Módulo V.Brasília, 2001.

.Combate aos Incêndios

Florestais. Associação Brasileira de Agricultura Superior, Universidade Federal do Paraná, Curso de Especialização - Módulo VI. Brasília 2001. 